\title{
Patient safety on weekends and weekdays: A comparative study of two hospitals in California
}

\author{
Alberta T Pedroja ${ }^{1}$, Mary A Blegen ${ }^{2}$, Rebecca Abravanel ${ }^{3}$, Arnold J Stromberg ${ }^{4}$, Bruce Spurlock ${ }^{3}$ \\ 1. ATP Healthcare Services, LLC, Los Angeles, CA, USA. 2. Community Health Systems, School of Nursing, University of \\ California San Francisco, San Francisco, CA, USA. 3. Cynosure Health, Sacramento, CA, USA. 4. Department of Statistics, \\ University of Kentucky, Lexington, KY, USA
}

Correspondence: Alberta T Pedroja. Address: ATP Healthcare Services, LLC, Los Angeles, CA, USA.

E-mail: apedroja@atphs.com

Received: November 17, 2012 Accepted: February 21, 2013

Online Published: March 14, 2013

DOI : $10.5430 /$ jha.v2n3p66

URL: http://dx.doi.org/10.5430/jha.v2n3p66

\section{Abstract}

Background: Most clinicians believe that hospitals are less safe on the weekends, but the research findings have been mixed. In addition, the investigations have largely examined the outcomes of patients admitted on weekends versus weekdays and not patient harm that occurred on weekends against patient harm that occurred during the week.

Objective: To compare the extent of patient harm that occurred on weekend days with the harm that occurred on weekdays.

Methods: Using daily incident report data for an entire year from two hospitals in California we measured the number of incidents each day, the average harm per incident, and the total daily harm from all incidents. Analyses were done separately for the two different hospitals and controlled for daily patient census. Harm per incident was assessed to determine whether reporting patterns on weekdays differed from weekends.

Results: There were fewer incidents per day and less total daily harm on weekend days than days during the workweek in both hospitals $(p<.05)$. Patient to nurse ratios are held at the same level across all days and shifts. There did not appear to be a systematic tendency to under-report incidents on the weekends.

Conclusion: The data strongly suggest that there is less harm to patients due to healthcare error on the weekends than during the week. Further work is needed to determine whether these findings would apply in hospitals with varying staffing levels.

\section{Key words}

Weekends, Patient safety, Error, Complex adaptive systems, Hospital systems load

\section{Introduction}

Most clinicians believe that hospitals are less safe on the weekends, and patient harm due to medical mistakes is more frequent on weekends than during the week ${ }^{[1]}$. The data that support this belief have largely examined the outcomes of 
patients admitted on weekends and not the bulk of patients present on weekends. Given the importance of finding ways to improve the safety and quality of patient care, further investigation into this issue is needed.

In this study we examined patient harm on weekdays compared to harm that occurred on weekends. Two hospitals in California provided self-reported incidents that included a code for the injury sustained as a result of errors. This enabled us to make a comparison between the patient harm resulting from incidents that occurred on the weekends and the injury associated with incidents reported during the workweek. This study sought to confirm or deny the widely held belief that more errors occur on the weekends.

Since the publication of To Err Is Human ${ }^{[2]}$ and the focus on patient safety, there has been a concern that patient safety erodes on the weekends, but investigations have not been uniformly supportive of this phenomenon. The meta-analysis performed by Cavallazzi and colleagues in $2010^{[3]}$ found a greater risk of mortality for patients admitted on the weekends as long as there was no difference in the level of nursing staff caring for patients, but a 2007 review of the literature ${ }^{[4]}$ found that of the eight complications studied, five were adversely affected on the weekends and three were not. A few studies found a modest deterioration on the weekends ${ }^{[5,6]}$, and some none at all ${ }^{[7-10]}$. In fact, in some studies, mortality, length of stay, and unplanned transfers to the ICU were favorably impacted when patients were admitted on the weekend ${ }^{[11-13]}$. Becker ${ }^{[14]}$ tried to reconcile these mixed reviews citing differences in medical conditions and the importance of immediate care for emergencies, which are proportionally greater on weekends and have a greater risk of mortality. However, Redelmeier ${ }^{[1]}$ concluded that the evidence suggesting a greater risk of mortality on the weekends was inconclusive.

Recent investigators ${ }^{[15,16]}$ have suggested that healthcare delivery is a complex adaptive system (CAS) which may account for these mixed results. Clinicians and others in the healthcare environment termed "agents" by complexity scientists have the capacity to learn and behave in unpredictable ways, and because of their interconnectedness, the actions of one may affect the whole in unpredictable ways ${ }^{[17]}$. Seen in this way, the weekends with less planned surgery and diagnostic tests are clearly less complex than the weekdays, and this difference may be able to account for the improved outcomes when staffing patterns are held constant.

Table 1. Harm score calculation - Example for one day

\begin{tabular}{lllll}
\hline Incident Harm level & Number of Incidents & Harm Multiplier & Calculation & Harm score \\
\hline Harm level - no level assigned & 0 & 0 & 0 & 0 \\
No harm: did not reach patient & 7 & $1^{2}$ & $7 * 1$ & 7 \\
No harm: reached patient & 8 & $2^{2}$ & $8 * 4$ & 32 \\
Minimal harm or impact & 2 & $3^{2}$ & $2 * 9$ & 18 \\
Moderate harm or impact & 1 & $4^{2}$ & $1 * 16$ & 16 \\
Serious harm or impact & 0 & $5^{2}$ & $0 * 25$ & 0 \\
Patient death & 0 & $6^{2}$ & $0 * 36$ & 0 \\
& & SUM & 73 \\
Patient Census 440 & & Daily Harm Score & .17 \\
\hline
\end{tabular}

In California the nurse-to-patient ratios are set via legislation, California Assembly Bill (AB394), and these do not vary for nights or weekends. Therefore comparing errors on weekdays and weekends should allow us to determine whether it is actually safer on weekends when the hospital systems load is less and staffing patterns are held constant.

\section{Methods}

Two hospitals provided self-reported incidents for a one-year period for our measure of patient harm. Each incident report included a code according to the level of harm sustained as a result of the error using a scale from 0 to 6 . The codes 
represented the following: $0=$ unable to determine, $1=$ no harm, or did not reach patient, $2=$ no harm, reached the patient, $3=$ reached patient with minimal harm, $4=$ moderate harm, $5=$ serious harm, $6=$ death. The measure of harm used for this study was taken from previous work on patient safety ${ }^{[18]}$. Patient harm and harm per patient were the sum of the weighted incidents. The multiplier used to weight each incident for patient harm was the square of the injury scale. Table 1 provides a sample calculation for a single day. Approximately 5\% of the incidents in Hospital A and $2 \%$ in Hospital B had no value and were not included in the analyses because they were assigned a zero, meaning unable to determine.

Each hospital was analyzed separately. The two hospitals differed markedly in terms of size, community, services offered and expectations for provider reports of patient incidents accounting for the differences in incidents per day reported and the harm per incident. Therefore, combining the datasets, while possible, would be ill-advised.

Patient harm was summarized in several ways: average incidents per day, average total harm per day, average harm per patient per day, average harm per incident. CAS theory would expect to find fewer incidents on the weekends (average incident per day) due to the reduced complexity, less harm per day and less harm per patient if it was safer on the weekends, but average harm per incidents should be the same or similar if the reporting patterns do not change on the weekend. Average incidents per day reflect the number of incidents reported each day for weekends and weekdays. We expect fewer incidents on the weekends if it is safer. Average total daily harm is the sum of all harm on each day and average harm per patient illustrates the harm adjusted for the number of patients on that day. If weekends are safer, both of these will be lower. However, given the problems associated with self-reports, it would be important to know that there was no difference in the likelihood of reporting between weekends and weekdays. For example, if self-reporting on the weekends was lower except for those incidents where serious harm occurred, then it would be fair to say that fewer incidents was an artifact of self-reporting. But, if harm per incident was similar to weekdays, then the likelihood of decreased reporting on weekends is less.

Table 2. Frequency of incidents at each harm level

\begin{tabular}{|c|c|c|c|c|c|c|c|c|}
\hline \multirow{3}{*}{ Harm Level } & \multicolumn{4}{|c|}{ Hospital A: 470 Beds } & \multicolumn{4}{|c|}{ Hospital B: 280 Beds } \\
\hline & \multirow{2}{*}{$\begin{array}{l}\text { All Days } \\
\mathrm{N} \\
\end{array}$} & \multirow{2}{*}{ Per-cent } & \multirow{2}{*}{$\begin{array}{l}\text { Weekdays } \\
\mathbf{N} \\
\end{array}$} & \multirow{2}{*}{$\begin{array}{l}\text { Weekends } \\
\mathbf{N} \\
\end{array}$} & \multirow{2}{*}{$\begin{array}{l}\text { All Days } \\
\mathbf{N} \\
\end{array}$} & \multirow{2}{*}{ Per-cent } & \multirow{2}{*}{$\begin{array}{l}\text { Weekdays } \\
\mathbf{N} \\
\end{array}$} & \multirow{2}{*}{$\begin{array}{l}\text { Weekends } \\
\mathrm{N} \\
\end{array}$} \\
\hline & & & & & & & & \\
\hline $\begin{array}{l}\text { No harm: did not reach } \\
\text { patient }\end{array}$ & 998 & $13 \%$ & 775 & 223 & 32 & $2 \%$ & 28 & 4 \\
\hline $\begin{array}{l}\text { No harm: reached } \\
\text { patient }\end{array}$ & 3,446 & $44 \%$ & 2,591 & 855 & 980 & $68 \%$ & 740 & 240 \\
\hline $\begin{array}{l}\text { Minimal harm or } \\
\text { impact }\end{array}$ & 2,319 & $30 \%$ & 1,782 & 537 & 391 & $27 \%$ & 304 & 87 \\
\hline $\begin{array}{l}\text { Moderate harm or } \\
\text { impact }\end{array}$ & 959 & $12 \%$ & 735 & 224 & 34 & $2 \%$ & 27 & 7 \\
\hline Serious harm or impact & 106 & $1 \%$ & 79 & 27 & 2 & $.002 \%$ & 1 & 1 \\
\hline Patient death & 9 & $.001 \%$ & 8 & 1 & 1 & $.001 \%$ & 1 & 0 \\
\hline TOTAL & 8,634 & $100.0 \%$ & 6,576 & 2,058 & 1452 & $100.0 \%$ & 1,110 & 629 \\
\hline $\begin{array}{l}\text { Average incidents / } \\
\text { day }\end{array}$ & & & 25.2 & 19.6 & & & 4.2 & 3.3 \\
\hline $\begin{array}{l}\text { Average harm / } \\
\text { incident }\end{array}$ & & & 2.85 & 2.78 & & & 2.35 & 2.35 \\
\hline
\end{tabular}


To determine whether patient safety differs between weekdays and weekends, a t-test was performed on average incidents per day, average total harm per day, average harm per patient per day, average harm per incident. If reporting behaviors are similar, we would expect average harm per incident to be statistically similar. If patient harm was less on the weekends, the other measures would be different at the .05 level.

\section{Results}

We received data from each hospital for 365 days. One hospital was an academic teaching hospital and the other was a community general hospital. Weekends took 105-106 days and weekdays took the remaining 260-261 days. (One dataset included February 29th.) In all, we received data on 11,311 incidents with a harm score attached; 8,634 from the larger Hospital A (470 beds) and 2,677 from Hospital B (280 beds). Hospital A had an average daily census on the weekdays of 462 and 427 on the weekends. Hospital B had an average daily census of 270 on the weekdays and 249 on the weekends. Both hospitals had significantly fewer patients on the weekends.

Patient and location identifiers had been removed before transmitting the data. Of all the incidents, 6,844 (61\%) were scored as 1 or 2 - no harm or did not reach the patient. 38\% was divided between minimal and moderate harm. Approximately $1 \%$ of the incidents resulted in serious harm (114) or death (10). The distribution of patient harm at both hospitals had a positive skew on weekends and weekdays although the community hospital was proportionally busier on the weekend than the academic medical center that provides tertiary care (see Table 2).

Table 3. Patient Harm by Hospital

\begin{tabular}{|c|c|c|c|c|c|}
\hline & $\begin{array}{l}\text { Average Daily } \\
\text { Census }\end{array}$ & $\begin{array}{l}\text { Average Incidents/ } \\
\text { Day }\end{array}$ & $\begin{array}{l}\text { Average Total Harm/ } \\
\text { Day }\end{array}$ & $\begin{array}{l}\text { Average Harm/ } \\
\text { Patient/Day }\end{array}$ & $\begin{array}{l}\text { Average Harm/ } \\
\text { Incident }\end{array}$ \\
\hline \multicolumn{6}{|c|}{ Hospital A } \\
\hline Weekday & 462 (29) & 25.2 & 71.2 (24.9) & $.154(0.052)$ & $2.85(0.67)$ \\
\hline Weekend & $427(24)$ & 19.6 & $54.3(21.6)$ & $.127(0.050)$ & $2.78(0.77)$ \\
\hline$p$ & $<0.0001$ & $<0.0001$ & $<0.0001$ & $<0.0001$ & 0.3369 \\
\hline \multicolumn{6}{|l|}{ Hospital B } \\
\hline Weekday & 270 (19) & 4.2 & $18.4(9.3)$ & $.068(.03)$ & $2.35(0.77)$ \\
\hline Weekend & 249 (15) & 3.3 & 13.9 (7.5) & $.056(.03)$ & 2.35 (1.04) \\
\hline$p$ & $<0.0001$ & 0.0002 & $<0.0001$ & 0.0017 & 0.9287 \\
\hline
\end{tabular}

The pattern of incidents voluntarily reported by the staff does not appear to be different between weekdays and weekends as the harm per incident in Hospital A had a level of 2.85 on weekdays and 2.78 on weekends. Hospital B was 2.35 on weekdays and weekends. Neither difference was statistically significant (see Table 3).

Hospital A had an average of 25.2 incidents per day on weekdays and 19.6 incidents per day on weekends. Hospital B demonstrated a similar pattern, 7.8 incidents per day on weekdays and 6.0 incidents per day on the weekends. Both differences were statistically significant at the .05 level. The average total daily harm for Hospital A was 71.2 on weekdays and 54.3 on weekends and 18.4 versus 13.9 for weekdays and weekends respectively, for Hospital B. Both differences were statistically significant.

When controlling for the patient census, harm per patient differed significantly, as well. Hospital A had a per patient harm score of .154 on weekdays and .127 on weekends. Hospital B had per patient harm scores of .068 and .056 on weekdays and weekends, respectively. Therefore, the number of incidents and the total and average patient harm was lower on the weekends. 


\section{Conclusions}

The foregoing results suggest that, holding nurse-to-patient ratios constant, the weekends are safer than the weekdays. There was no difference in the harm per incident reported on the weekends minimizing the possibility that the reporting patterns differed. There were more incidents during the week, there was more harm on each day, and per patient harm was greater. It is important to note the significance of per patient harm. It might be argued that since the census is higher, there is more opportunity for harm so the average daily harm might be expected to be greater. However, because per patient harm is also significantly different, we had to look for other possible explanations.

The relative difference in patient safety likely occurs because there is less activity in the hospital on weekends. Elective surgeries and scheduled tests and treatments occur more often during the week. Only the emergency department may have an uptick in patients seen and level of complexity. With less complexity, the workload is less and fewer errors that can lead to patient harm occur. Though further research is needed on adverse events for patients admitted during the weekends compared to patients in the consequent days of the stay, Luyt ${ }^{[12]}$ and Morales ${ }^{[13]}$ provided similar explanations when they found that mortality was not impacted by care on the weekend. They cited fewer delays for tests and treatments, reduced workload for nurses, and other things that reduce hospital systems load. Hence, with nurse staffing held constant, it is possible that it is not census by itself or severity of illness, but the level of complexity that may be causal. Additional research is needed to understand the nature of healthcare complexity and the relationship between complexity and patient harm in a complex adaptive system to support these findings.

The challenges of studying rare events are well known, but using incident reports, so often maligned due to under-reporting, has proved to be a useful tool in this study. In the past, we have been confined to studying the effect of patients admitted or discharged on the weekend to discern a difference in patient harm due to human error ${ }^{[19-21]}$. With this method, we have the opportunity to consider all errors committed on the weekend compared to errors committed during the week and compare the severity of each. So long as the reporting patterns do not change, we can compare hospital performance during the week to that on the weekends. This may be important because the steps needed to improve patient safety may differ between weekends and weekdays. Aggregating hospital performance or comparing one hospital to another is not advisable given differences in the level of transparency that does not have an acceptable metric at the current time.

Comparisons of results from different methods of finding patient harm from healthcare errors (provider self-reports, Patient Safety Indicators (PSIs), Global Trigger Tool (GTT)) concluded that there is little overlap in the types of events detected by each method and that each approach has strengths and limitations ${ }^{[22,23]}$. PSIs tend to capture events associated with surgery and other procedures and provider reported events tend to focus on care of the patients without specific procedures or after the procedures are completed ${ }^{[23-25]}$. Provider self-reports captured process problems and major sentinel events after surgery but not the other events in the course of patient recovery. Triggered chart review using the GTT, on the other hand, captured adverse events associated with physician care for both surgical and non-surgical patients but few of the adverse events of non-physician providers. Naessens and colleagues ${ }^{[23]}$ conclude "that provider-reported events, being more sensitive indicators of patient safety during hospitalization, may be a better indicator of lower quality of care than PSIs” (pg 306).

This study does have other limitations. The effect was seen in two California hospitals and needs wider application to be certain. Future studies would need to take into account the patient to nurse ratios on the weekends if different from those on weekdays. In addition, using incident reports likely assures under-reporting. Though Naessens ${ }^{[23]}$ concluded that incidents reports were likely the most sensitive source of information about patient safety during hospitalization, further research is needed to check the veracity of these findings. 
While staffing is a major contributor to patient outcomes ${ }^{[26,27]}$, there may be other confounding variables such as the availability of hospitalists, residents or physicians on-call or the speed at which diagnostic procedures are available. Additional research is needed to investigate the effect of these and other influences.

Nevertheless, the widespread belief that patients are at greater risk of harm on the weekends must be questioned. The findings reported in this study suggest that, keeping nurse staffing patterns constant, the likelihood of patient harm due to medical mistakes is less likely on the weekend. Ruling out the ratio of nurse to patients, this study suggests that with less activity the hospital system can function more smoothly and facilitate the care of the patients with less risk of patient harm.

\section{Funding}

Funding for this project was provided by the Gordon and Betty Moore Foundation.

\section{Acknowledgements}

Appreciation also goes to the hospital members of the Bay Area Patient Safety collaborative.

\section{References}

[1] Redelmeier DA, Bell CM. Weekend worriers. N Engl J. 2007; 356: 1164-1165. PMid:17360995 http://dx.doi.org/10.1056/NEJMe068310

[2] Kohn LT, Corrigan JM, Donaldson MS. America IOM (COQOHCI). To Err is Human: Building a Safer Health System, in Committee on Quality and Healthcare in America. Institute of Medicine. Washington, DC: National Academy Press; 2001.

[3] Cavallazzi R, Marik PE, Hirani A, Monvasi P, Tajender SV, Leiby BE. Association between Time of Admission to the ICU and Mortality: A Systematic Review and Metaanalysis. Chest. 2010; 138: 68-75. PMid:20418364

[4] Bendavid R, Kaganova Y, Needleman J, Gruenberg L, Weissman JS. Complication rates on weekends and weekdays in US hospitals. Am J Med. 2007; 120: 422-428. PMid:17466653 http://dx.doi.org/10.1016/j.amjmed.2006.05.067

[5] Barnett MJ, Kaboli PJ, Sirio CA, Rosenthal GE. Day of the week of intensive care admission and patient outcomes: a multisite regional evaluation. Med Care. 2002; 40: 530-539. PMid:12021679 http://dx.doi.org/10.1097/00005650-200206000-00010

[6] Ensminger SA, Morales IJ, Peters SG, Keegan MT, Finkleman JD, Lymp JF, et al. The hospital mortality of patients admitted to the ICU on weekends. Chest. 2004; 126: 1292-1298. PMid:15486395 http://dx.doi.org/10.1378/chest.126.4.1292

[7] Gould JB, Qin C, Marks AR, Chavez G. Neonatal mortality in week- end vs. weekday births. JAMA. 2003; 289 : $2958-2962$. PMid:12799403 http://dx.doi.org/10.1001/jama.289.22.2958

[8] Laupland KB, Shahpori R, Kirkpatrick AW, Stelfox HT. Hospital mortality among adults admitted to and discharged from intensive care on weekends and evenings. J Crit Care. 2008; 23: 317-324. PMid:18725035 http://dx.doi.org/10.1016/j.jcrc.2007.09.001

[9] Meynaar IA, van der Spoel JI, Rommes JH, van Spreuwel-Verheijen M, Bosman RJ, Spronk PE. Off hour admission to an intensivist-led ICU is not associated with increased mortality. Crit Care. 2009; 13: R84 PMid:19500333 http://dx.doi.org/10.1186/cc7904

[10] Khanna R, Wachsberg K, Marouni A, Feinglass J, Williams MV, Wayne DB. The association between night or weekend admission and hospitalization-relevant patient outcomes. J Hosp Med. 2011; 6: 10-14. PMid:21241035 http://dx.doi.org/10.1002/jhm.833

[11] Arias Y, Taylor DS, Marcin JP. Association between evening admissions and higher mortality rates in the pediatric intensive care unit. Pediatrics. 2004; 113: e530-534. PMid:15173533 http://dx.doi.org/10.1542/peds.113.6.e530

[12] Luyt CE, Combes A, Aegerter P, Guidet B, Trouillet JL, Gilbert C, et al. Mortality among patients admitted to intensive care units during weekday day shifts compared with “off” hours. Crit Care Med. 2007; 35: 3-11. PMid:17080000 http://dx.doi.org/10.1097/01.CCM.0000249832.36518.11

[13] Morales IJ, Peters SG, Afessa B. Hospital mortality rate and length of stay in patients admitted at night to the intensive care unit. Crit Care Med. 2003; 31: 858-863. PMid:12626997 http://dx.doi.org/10.1097/01.CCM.0000055378.31408.26

[14] Becker DJ. Do hospitals provide lower quality care on weekends? Health Serv Res. 2007; 42: 1589-1612. PMid:17610439 http://dx.doi.org/10.1111/j.1475-6773.2006.00663.x

[15] Berwick DM. The science of improvement. JAMA. 2008; 299: 1182-1184. PMid:18334694 http://dx.doi.org/10.1001/jama.299.10.1182 
[16] Wesorick B, Doebbeling B. Lessons from the Field: The Essential Elements for Point-of-Care Transformation. Med Care. 2011 ; 49 Suppl: S49-S58. PMid:21705920 http://dx.doi.org/10.1097/MLR.0b013e3182239331

[17] Crabtree BF, Nutting PA, Miller WL, McDaniel RR, Stange KC, Jaen CR, et al. Primary Care Practice Transformation is Hard Work, Insights From a 15-year Developmental Program of Research. Med Care. 2011; 49 Suppl: S28-S35. PMid:20856145 http://dx.doi.org/10.1097/MLR.0b013e3181cad65c

[18] Pedroja AT. The tipping point: the relationship between volume and patient harm. Am J Med Qual. 2008; $23: 336-341$. PMid:18820138 http://dx.doi.org/10.1177/1062860608320628

[19] Aylin P, Yunus A, Bottle A, Majeed A, Bell D. Weekend mortality for emergency admission: A large multicentre study. Qual Saf Health Care. 2010; 19: 213-217. PMid:20110288 http://dx.doi.org/10.1136/qshc.2008.028639

[20] Cram P, Hillis SL, Barnett M, Rosenthal GE. Effects of weekend admission and hospital teaching status on in-hospital mortality. Am J Med. 2004; 117: 151-157. PMid:15276592 http://dx.doi.org/10.1016/j.amjmed.2004.02.035

[21] Bell CM, Redelmeier DA. Mortality among patients admitted to hospitals on weekends as compared with weekdays. N Engl J Med. 2001; 345: 663-668. PMid:11547721 http://dx.doi.org/10.1056/NEJMsa003376

[22] Levinson DR. Adverse events in hospitals: Methods for identifying events. Office of Inspector General, Dept of Health and Human Services 2010. OEI 060800221.

[23] Naessens JM, Campbell C, Huddleston JM, Berg BP, Lefante JJ, Williams AR, et al. A comparison of hospital adverse events identified by three widely used detection methods. Int J Qual Health Care. 2009; 21: 301-307. PMid:19617381 http://dx.doi.org/10.1093/intqhc/mzp027

[24] de Vries EN, Ramrattan M, Smorenburg S, Gouma DJ, Boermeester MA. The incidence and nature of in-hospital adverse events: a systematic review. Qual and Saf in Healthcare. 2008; 17: 216-223. PMid:18519629 http://dx.doi.org/10.1136/qshc.2007.023622

[25] Stockwell DC, Kane-Gill SL. Developing a patient safety surveillance system to identify adverse events in intensive care units. Crit Care Med. 2010; 38: S117-S125. PMid:20502165 http://dx.doi.org/10.1097/CCM.0b013e3181dde2d9

[26] Blegen MA , Goode CJ, Spetz J. Nurse staffing effects on patient outcomes: Safety-net and non-safety-net hospitals. Med Care. 2011; 409: 406-414.

[27] Unruh LY, Zhang NJ. Nurse staffing and patient safety in hospitals. Nurs Res. 2012; 61: 3-12. PMid:22166905

http://dx.doi.org/10.1097/NNR.0b013e3182358968 